\title{
A FrameWORK OF THE BACHELOR OF TECHNOLOGY CONCEPT AND ITS SigNIFICANT EXPERIENTIAL LEARNING COMPONENT
}

\author{
Dan Centea*, Ishwar Singh, Lucian Balan, Timber Yuen \\ Faculty of Engineering, McMaster University, Hamilton, ON, Canada \\ *Corresponding author: centeadn@mcmaster.ca
}

\begin{abstract}
The paper describes various elements of the experiential learning methodologies prescribed in the Automotive and Vehicle Technology (AVT) program. It first discusses the approaches that different instructors take to achieve the course outcomes by using different course delivery models and techniques. It then addresses an implementation of Kolb's cycle by presenting different level of experiential learning applied in the program. Several implementations of the experiential learning are presented, and the corresponding student experience is described. At the end, the paper presents a comparison between the skills that the graduates are expected to acquire and the actual student skills reported by employers. The paper concludes with an analysis of the results of the experiential learning approach offered by the AVT program.
\end{abstract}

Keywords: Experiential learning, engineering education, student skills, Bachelor of Technology, Automotive and Vehicle Technology

\section{INTRODUCTION}

Classroom instruction approaches have evolved considerably in the last 40 years through the development of several teaching and learning methods that include active learning, collaborative learning, student-centered learning, problem based learning (PBL), and experiential learning.

Experiential learning is a powerful teaching and learning approach that allows learners to develop skills and knowledge by personal experience and involvement. Experience plays a central role in the learning process, "the process whereby knowledge is created through the transformation of experience" [8].

Although early work on experiential learning was introduced in early 1900's by John Dewey [5], Kurt Lewin, Jean Piaget, William James, Carl Jung, Paulo Freire, Carl Rogers and others [8], the Experiential Learning Theory (ELT) and the Experiential Learning
Model (ELM) developed, in the early 1970s by David Kolb [9], [10], [12], gave a concrete shape for practical applications and guidelines for designing and developing practical curriculum. ELM is composed of four elements included in a repeating cycle: concrete experience, reflective observation, abstract conceptualization, and active experimentation. These four elements are grouped in the ELT, as described by Baker and Kolb in [2], into two modes of grasping experience - apprehension (concrete experience) and comprehension (abstract conceptualization) - and two modes of transforming experience - intension (reflective observation) and extension (active experimentation). Individual learning styles are determined by an individual's preferred way of feeling (concrete experience), thinking (abstract conceptualization), reflecting (reflective observation) and acting (active experimentation) [7]. Kolb notes in [2] that the ELT learning model suggests that learning requires individuals to resolve abilities that are polar opposites, and that the learner must continually choose which set of learning abilities he or she will use in a specific learning situation.

Engineering profession requires both conceptual knowledge and hands-on experience, and therefore experiential learning can be used for teaching and learning of engineering topics [11]. Engineering programs have been proven to be successfully implemented through experiential learning activities [6].

Bodner presents in [3] the design of a role-based experiential learning environment for logisticians involved in military education. Considering that learning through a medium that combines course materials with game characteristics can be a powerful tool for engineering education, Siddique [15] shows that students using the game module, when compared with lecture-based instruction, had significant improvements when addressing questions that involved higher-order cognition.

Montequin et al [13] assess engineering teams in project based learning, a methodology that emphasizes instruction by assigning projects. Adams et al examine in 
[1] the application of experiential learning principles to six areas of team functioning - purpose, membership, roles, context, process, and action taking - and describe how team effectiveness can be improved.

Experiential learning activities can be applied at different levels in engineering education. This paper defines the framework used in the development of the Bachelor of Technology (B.Tech.) programs offered at McMaster University, describes the teaching and learning methods used in several courses offered in the Automotive and Vehicle Technology (AVT) program, and provides some details about different elements of experiential learning approaches.

\section{BACHELOR OF TECHNOLOGY CONCEPT}

McMaster University's Faculty of Engineering and Mohawk College's School of Engineering Technology have partnered to establish the B.Tech. degree program in response to the needs of today's innovation-based organizations. Initially developed to provide opportunities for college graduates to obtain a university degree and offer programs that are relevant to the needs of industry and businesses, the current B.Tech. programs offer both 4year degree programs for high school graduates and degree completion programs for college graduates.

The B.Tech. approach provides flexibility to design, develop and modify the courses that combine theoretical and applied engineering components with a significant amount of experiential learning content to address the needs of the employers.

The current B.Tech. curricula includes theoretical knowledge related to basic engineering studies, major applied engineering components, and significant complimentary studies that provide students with a series of management and soft skills. Each technical course has a laboratory component that provides practical hands-on skills. These combinations of theoretical foundations and practical skills prepare them to gain industrial experience in a 12 month mandatory co-op employment.

The combination of theoretical engineering knowledge management perspective, hands-on laboratory program including a technical report project, and co-op experience provide the graduates a set of skills highly valued by employers.

\section{BACHELOR OF TECHNOLOGY FRAMEWORK}

\subsection{Course Delivery Methods and Techniques}

Today's curriculum development is focused on providing a series of leaning outcomes to students. An efficient way to provide the desired leaning outcomes is to adapt the course content to an effective delivery model and technique.

The courses offered in B.Tech.'s AVT program are delivered using several teaching and learning approaches methods that combine traditional lecturing methods with active learning, collaborative learning, problem-based learning, and experiential learning approaches. Implementations of these approaches are described below.

While traditional lecturing methods are an excellent method for providing fundamental knowledge to students, pure lecturing methods tend to be less efficient due to the amount of information available to students. Many university courses offered today make use of an online learning management system that is used by course instructors to provide a significant amount of course materials like lecture notes, solved examples, assignment solutions, previous tests and exams, and case studies. With so much online course materials available at any time students' attendance is often significantly reduced if courses do not include active learning components that encourage students to attend classes. Studies have shown that students enjoy participating in different forms of active learning strategies and have stronger understanding of the concepts. With an average classroom size of 60 students, several courses offered in the AVT program use active learning approaches that include small-group activities related to solving analytical problems, mathematically modeling physical systems, using computer programs and packages to solve engineering problems, and case studies.

Collaborative learning is an important educational approach in which students engaged in a common task are accountable to each other. Although the active learning activities described above are also a form of collaborative learning, group projects is by far the most important collaborative learning approach in the courses offered in the AVT program. Most of the group projects are prepared outside the classroom environment and include face-to-face meetings, on-line discussions, file sharing, report writing, and presentations. Examples of group projects include modelling and designing components and assemblies in CAD courses, designing and manufacturing assemblies in a Manufacturing Processes course, and designing, implementing and testing open-ended automotive-related mechatronic projects undertaken in the last year of their studies as a capstone design or technical report project course.

Open-ended projects allow students to become creative problem solvers. Creativity requires inquiry-based teaching in which students need to perform brainstorming session, to identify new ideas, to question their own assumptions, to imagine other viewpoints, and to come up with a reasonable product that can be supported with engineering analyses. All open-ended projects prepared by the AVT students combine creativity with a rigorous 
engineering design process in which the specifications of the designed products are constantly compared with the initially defined system specifications. Students need often to find a balance between creativity, aspect, and the technical specification of the designed product.

As an example problem-based learning (PBL) is used in the Conceptual Design of Electric and Hybrid Electric Vehicles course offered in the AVT program. The conceptual design of a vehicle requires a large amount of information that cannot be taught in a single course using a traditional lecture-intensive approach. Furthermore, to learn the rapidly evolving knowledge related to electronics, controls, mechatronics, and vehicle communication for electric and hybrid electric vehicles, students are encouraged to perform many inquiry-based and problem-solving activities. PBL is an effective approach that allows students to perform these activities. To be an effective course, the problems that the students are required to explore need to use a combination of already taught and new knowledge, but also need to be interesting enough to trigger students' willingness to explore modern ideas. For instance, most students excelled in presenting futuristic smart-phone controlled user interfaces between the driver and the vehicle, but showed less interest towards the more traditional problem related to the conceptual design of the vehicle powertrain, parts of which are also covered in another course.

\subsection{Experiential Learning Approaches}

As described in the introduction, Kolb's [8] experiential learning cycle can be categorized into four phases: concrete experience, reflective observation, abstract conceptualization, and active experimentation. In the concrete experience phase students are introduced to the knowledge to be learned through active experiences such as lab sessions or field work. In the reflective observation phase, students consciously reflect back on the experience. They tend to ask a lot "why" questions. In the abstract conceptualization phase students form a theory or model of what is observed. In the last phase, students plan a series of experiments to test the effects of changing parameters on the theory or model. A detailed description various implementation of Kolb's learning cycle in several AVT courses is presented in [16].

The B.Tech programs provide opportunities for experiential learning as supported by the following elements of the program: hands-on labs, classroom and lab demonstrations, industry invited speakers, co-op program, technical report projects, use of industry relevant equipment either purchased for the program or donated by industry, and international engineering collaboration.
The experiential learning approach used in the majority of the B.Tech. technical courses implies an integration of the theory with a practical component. The laboratory experiments, generally used to reinforce the knowledge taught during the lectures, are correlated with the theory. Students learn the theoretical knowledge in the classroom and apply it after a very short time during the following laboratory session.

In four year of university education the B.Tech. students attend more than 550 lab hours. The hands-on labs include mechanical, thermal, fluid-mechanics, materials, electrical, electronic, and mechatronic experiments, computer programming, $\mathrm{CAD}$, and computer simulations.

The labs are delivered using structured and unstructured approaches. The labs of the fundamentals courses offered in the first two years of AVT studies generally use a structured approach. Students are asked to follow the steps of a defined procedure, to collect data, and to write reports. On the other hand the labs related to the upper-year courses include combinations of structured and unstructured approaches and include open ended projects selected and developed by students. It is interesting to notice that in most of the automotive-related labs related to control system, mechanical vibrations, mechatronic systems, electric and hybrid electric vehicles, manufacturing systems, multi-body dynamics, electrical and electronic systems, and vehicle dynamics the students are more motivated if they are allowed to choose their own project topics.

Lab experience includes writing $\mathrm{C}++$ and Visual Basic computer programs to solve engineering problems, using computer packages like AutoCAD, SolidWorks, Catia and NX to geometrically model various parts and assemblies, using models developed in ANSYS, CATIA, NX to perform engineering analyses, using simulation software like ADAMS, ADAMS/Car, Carsim, Matlab, and Simulink to perform simulations, and using various microcontroller-specific programming languages to develop mechatronic systems.

\subsection{Students' Experience}

The acceptance of a non-traditional teaching strategy is an important approach for any instructor who intends to include significant active learning components in the classroom. The student experience in courses that use the flipped classroom and the PBL approach, and the student experience in various experiential learning approaches are described below.

A comparison of the grades in mathematics course [14] taken by AVT students shows that the performance of the students taught via an intervention-based active learning approach like flipped classroom is significantly better than the students who learn the material via the traditional 
lecturing approach. Students learned the concepts via cooperative learning that makes the course more attractive. The approach had a positive impact on the student learning outcomes that gave students more confidence in the course materials. Students enjoyed the experience of learning by exploring the various solution possibilities. The overall performance was good and the class performance improved by nearly two letter grades.

The PBL approach used in the Conceptual Design of Hybrid Electric Vehicles course [4] was initially received with hesitation by the students. The acceptance of this approach constantly increased during the course. Most students were proud of their accomplishments, received good feedback and suggestions, provided by a panel of industry experts in the automotive field, after their presentations that included evidence to support their engineering decisions.

In the course evaluations the students report the experiential learning components of the curriculum in different ways. Most students provide positive comments about their lab experience. Student feedback include "the lab components and the lab project are invaluable"; "lab projects were valuable, fun, and allowed for independent thinking, problem solving and troubleshooting"; "handson labs were extremely beneficial to my understanding of automotive systems"; "class demonstrations are excellent"; "the lab component complemented the theory based lecture work extremely well". Meanwhile, in an upper year lab that contains some structured components students report that "labs could allow for more independent thinking as they seem to be more of a stepby-step following of a pre-written code". Overall, most students report their lab experience as very good.

\subsection{Student Skills}

Each course included in the AVT curricula lists a series of course learning outcomes that specify the skills and knowledge that the graduates will have upon the completion of the course. The assessment of the level in which these learning outcomes are met in various courses of the AVT program is done using statistical analysis and with feedback from employers.

One way of assessing student skills is to compare the grades of two sections of the same course delivered by the same instructor using different delivery approaches. The results of the Complex Analysis course taken by the AVT student and reported in [14] show that the final course grade was about $10 \%$ higher in the experimental section delivered with the well as the intervention-based active approach than in the section taught using the standard lecturing format.

The AVT program has a mandatory industrial co-op experience component in which the students are expected to be hired for three 4-month terms. Being a paid co-op, the competition is very high and, in order to be successful, students need to prove that they have the skills required by the job postings. Near the end of the employment period employers are required to fill out feedback form to report back to the university the technical skills, the soft skills, the work habits and the behaviour of the co-op students. Overall, these reports show that most of the skills provided by the university education match the skills that the employers expect the employees to have.

Another form of employer feedback can be obtained in a course that contains elements judged by industry and academic managers not related to the course. The purpose of the last semester AVT course reported in [4] is to prepare a conceptual design of an electric of hybrid electric vehicle. The course contains several experiential learning components applied through the PBL approach. The judging is done by the automotive industrial panel and university professors every year using clearly defined criteria using evaluation rubrics. The same panel of judges are invited every year to evaluate to projects and to provide feedback. Until the date of writing this paper they judged projects for three years in a row and suggested changes on the focus of some of the projects. The judge also provided suggestions related to the weight of different components in the evaluation rubrics in order to match them with the project evaluation criteria used in the automotive industry.

The employer feedback forms and suggestions provided by the panel of judges are used to compare the skills that the university program expects to provide to students with the skills reported by existing or potential employers and to perform adjustments to the courses if needed.

\section{CONCLUSIONS}

The newly created B.Tech. programs designed for secondary school graduates needed time and efforts to attract students. Specialization not offered at the engineering departments at McMaster University, a mandatory one year co-op approach, curricula that includes technical and management components, a partnership with a college that offers both theoretical and hands-on skills, and a significant experiential learning approach allowed the B.Tech. programs to reach the expected enrollment capacity of 240 students in only four years.

The paper focuses in the significant experiential learning components of the B.Tech's Automotive and Vehicle Technology programs. Non-traditional course delivery approaches, like flipped classroom and problem based learning, increase student attendance, participation and class interaction, and provide better learning outcomes compared with traditional course delivery 
approaches. Student-centred active learning strategies used in many courses involve all students attending the class in the learning process and ultimately provide a better learning experience compared with lecturecentered strategies. A balanced lecture-lab approach that includes significant experiential learning components offers an enjoyable leaning experience that provides handon skills.

One of main reasons of this success of the B.Tech. approach can be attributed to a proper balance between theory and structured experiential learning. Another reason of this success is attributed to the skills of the graduates that can be adapted to match the expectations of today's industry.

\section{References}

[1] Anna B. Adams, D. Christopher Kayes and David A. Kolb. "Experiential Learning in Teams," Simulation and Gaming, 2005, Vol 36(3), pp 330-354

[2] Ann C. Baker, Patricia J. Jensen and David A. Kolb, Conversation as Experiential Learning, In A. C. Baker, P. J. Jensen, D. A. Kolb and Associates, Conversational learning: An experiential approach to knowledge creation. Westport, CT: Quorum Books. 2002, 26 pp.

[3] Douglas A. Bodner, John. P. Wade, William R. Watson, and George I. Kamberov, "Designing an Experiential Learning Environment for Logistics and Systems Engineering." in Conference on Systems Engineering Research, C. J. J. Paredis, C. Bishop \& D. Bodner (ed), 2013 Vol. 16, pp. 1082-1091.

[4] Dan Centea and Seshasai Srinivasan and, "Problem Based Learning in the Conceptual Design of Hybrid Electric Vehicles" in Proc. IJCLEE International Joint Conference on the Learner in Engineering Education IJCLEE 2015 (San Sebastian, July 6-9 2015)

[5] John Dewey, Logic The Theory of Inquiry, New York, NY: 1938, 550 pp.

[6] Lee Harrisberger and others. Experiential Learning in Engineering Education, American Society for Engineering Education, Washington DC: 1976, 135 pp

[7] Paul Eickmann, Alice Kolb and David A. Kolb, "Designing learning," in Managing as designing, R. J.
Boland and F. Collopy (ed). Stanford: Stanford University Press, 2004, pp 241-247

[8] David A. Kolb. The Process of Experiential Learning, in David Kolb, The experiential learning: Experience as the source of learning and development. NJ: Prentice-Hall. 1984, $21 \mathrm{pp}$.

[9] David A. Kolb and Ron Fry, "Toward an Applied Theory of Experiential Learning," in Theories of Group Process, C. Cooper (ed.), London: John Wiley, 1975

[10] David A. Kolb, Experiential Learning: Experience as the Source of Learning and Development, Upper Saddle River, NJ: Pearson Education, 2015 (2nd ed.), 390 pp

[11] Daniel R. Lynch and Jeffrey S. Russell" Experiential Learning in Engineering Practice," J. Prof. Issues Eng. Educ. Pract, , 2009, Vol 135(1), pp 31-39

[12] Charalampos Mainemelis, Richard E. Boyatzis and David A. Kolb, "Learning Styles and Adaptive Flexibility. Testing Experiential Learning Theory," Management Learning, 2002, Vol 33(1), pp. 5-33

[13] Vicente Rodríguez Montequin, Julio M. Fernandez, J. Balsera and A. G. Nieto, "Using MBTI for the success assessment of engineering teams in project-based learning". International Journal of Technology and Design Education, 2013, Vol 23(4), pp. 1127-1146

[14] Seshasai Srinivasan and Dan Centea, "Applicability of Principles of Cognitive Science in Active Learning Pedagogies" in Proc. IJCLEE International Joint Conference on the Learner in Engineering Education IJCLEE 2015 (San Sebastian, July 6-9 2015)

[15] Zahed Siddique, C. Ling, P. Roberson, Y.J. Xu, and X.J. Geng, "Facilitating Higher-Order Learning Through Computer Games” Journal of Mechanical Design, 2013, Vol 135(12).

[16] Timber Yuen, D. Centea, L. Balan and I. Singh. "Construction of Mental Models in the Minds of Engineering Technology Students" in Proc. iCEER International Conference on Engineering Education and Research, iCEER2014 (Hamilton, ON, Aug. 24-26 2014) 